\title{
Preventing 'where next?' Patients, professionals and learning from serious failings in care
}

\author{
${ }^{1} \mathrm{D}$ Bell, ${ }^{2} \mathrm{~A}$ Jarvie \\ ${ }^{1}$ President, Royal College of Physicians of Edinburgh; ${ }^{2}$ Chair, Lay Advisory Group, Royal College of Physicians of Edinburgh and former Chief \\ Nursing Officer, Scottish Executive, Edinburgh, UK
}

KEYWORDS inquiries, NHS, patients, professionalism

DECLARATION OF INTERESTS No conflict of interest declared

\author{
Correspondence to $D$ Bell \\ Royal College of Physicians of \\ Edinburgh \\ 9 Queen Street \\ Edinburgh EH2 IJQ \\ UK
}

e-mail g.mcalister@rcpe.ac.uk

\section{INTRODUCTION}

Bristol, Oxford, Tunbridge Wells, Mid Staffordshire, Gosport, Lanarkshire, the Vale of Leven and Aberdeen are just some examples of places where NHS services have, in recent years, been the subject of inquiries or reviews regarding standards of medical and/or nursing care (Table I). Patients, NHS staff and the wider public may be forgiven for asking 'where next?', particularly as six of these inquiries have reported within the last two years. To both the casual observer and many working within the NHS, we have witnessed a trail of inquiries and reviews that have produced hundreds of detailed recommendations, which at face value appear to have had limited effect. One result has been increased inspection which, along with monitoring over time, may help to identify underlying problems. However, this places a significant additional resource burden on the already over-stretched NHS due to the considerable professional time required to contribute directly to the process. It may also adversely affect staff morale. The overwhelming majority of patients receive a high standard of medical and nursing care in the UK, but where serious failings have occurred how can we ensure lessons are learned? Why have these failings happened and how can we ensure they are not repeated?

\section{RESPONSES TO FAILINGS IN CARE}

It is clear when reviewing the publicly reported failings in care over the last I 5 years that the recommendations most embraced by policymakers have been at a statutory level and regard regulation and inspection. In parallel, the regulation and inspection bodies in England and Scotland have also undergone change (Figure I). Regulation and inspection has moved on from the days of a single prearranged annual visit to the more meaningful, ongoing, collection of data which enables outlying performance and indicators to be identified, monitored and investigated, with routine inspections or in-depth on-site inspection where required. While patients, staff and politicians may be concerned that there has been an increase in the level of serious failings in care reported, this may in part relate to increased inspection and improved reporting systems rather than necessarily reflecting deteriorating standards of care. Either way we must not be complacent. Further research is required to better understand the extent of the problem. Evidence emerging from the recent major inquiries has also suggested a loss of compassion - the heart of healthcare. While regulation and inspection provide a valuable means of independent assessment, they will not prevent recurrences alone. It is necessary not only to better understand why at times NHS services appear less patient-focused and compassionate, but to develop systems that support healthcare professionals to deliver high quality care.

\section{LEARNING FROM EXPERIENCE}

In his evidence to the Mid Staffordshire Inquiry in 20 I I, chaired by Sir Robert Francis QC, Professor Sir lan Kennedy, one of the UK's most experienced participants in examining failings in care, recounted his experience as Chair of the Bristol Inquiry and the initial Health Commission Inquiry into Mid Staffordshire.' In addition to drawing similarities between the events under investigation he noted that 'the history of the NHS is littered with the reports of Inquiries and Commissions: most have been consigned to gather dust on shelves' and asked 'what is it about healthcare and the NHS that it does not seem able to learn lessons...to prevent their recurrence?' More recently, in an interview given at the time of the publication of the Francis Report, he reflected that the problems in Mid Staffordshire were less about a lack of regulation and structural defects 'they are about the people who are looking after patients and the people who are leading the people 
TABLE I Published reports of major inquiries and reviews into serious failings in hospital care in the UK, 2000-2014

\begin{tabular}{|c|c|c|c|}
\hline 2001 & $\begin{array}{l}\text { Bristol } \\
\text { Public Inquiry into children's } \\
\text { heart surgery at the Bristol Royal } \\
\text { Infirmary 1984-95. Found serious } \\
\text { clinical and organisational failings } \\
\text { resulting in 30+ more child deaths } \\
\text { than if service had met standards. }\end{array}$ & & \\
\hline 2006 & $\begin{array}{l}\text { Stoke Mandeville } \\
\text { Healthcare Commission Inquiry } \\
\text { into outbreaks of Clostridium difficile } \\
\text { infection in 2004-05 which resulted } \\
\text { in over } 30 \text { patient deaths. Found } \\
\text { widespread management and infec- } \\
\text { tion control failings. }\end{array}$ & & \\
\hline 2007 & $\begin{array}{l}\text { Maidstone and Tunbridge Wells } \\
\text { Healthcare Commission Inquiry } \\
\text { into outbreaks of Clostridium difficile } \\
\text { infection in } 2005-06 \text { which resulted } \\
\text { in the deaths of } 90 \text { patients. Found } \\
\text { widespread management and infec- } \\
\text { tion control failings. }\end{array}$ & & \\
\hline 2010 & $\begin{array}{l}\text { Oxford } \\
\text { Independent review of children's } \\
\text { heart surgery at John Radcliffe } \\
\text { Hospital, Oxford, in } 2009-10 \text { fol- } \\
\text { lowing the deaths of four babies. } \\
\text { Found inadequate supervision and } \\
\text { clinical management. This hospi- } \\
\text { tal had also been the subject of } \\
\text { earlier reviews into poor working } \\
\text { relations (NHS review, 2000) and } \\
\text { a Healthcare Commission review } \\
\text { of adult cardiothoracic surgery } \\
\text { (2007), initially triggered in } 2004 \text { by } \\
\text { concerns regarding possible above } \\
\text { average mortality rates in children's } \\
\text { cardiothoracic surgery. }\end{array}$ & & \\
\hline 2013 & $\begin{array}{l}\text { Mid Staffordshire } \\
\text { Public Inquiry into Mid Stafford- } \\
\text { shire NHS Trust 2005-09. Found } \\
\text { serious failings at all levels (nursing, } \\
\text { medical and management) resulting } \\
\text { in poor care and 400-1200 more } \\
\text { deaths than if service had met } \\
\text { standards. }\end{array}$ & $\begin{array}{l}\text { Gosport } \\
\text { Review into } 92 \text { elderly patient } \\
\text { deaths at Gosport War Memo- } \\
\text { rial Hospital, Hampshire from } \\
\text { I } 998-2001 . \text { Found care failings. } \\
\text { Subject of further inquiry. }\end{array}$ & $\begin{array}{l}\text { Lanarkshire } \\
\text { Rapid Review of Acute Care in } \\
\text { NHS Lanarkshire. Conducted after } \\
\text { above average mortality rates were } \\
\text { reported. Found widespread failings } \\
\text { in care. }\end{array}$ \\
\hline 2014 & $\begin{array}{l}\text { Abertawe Bro Morgannwg } \\
\text { (Swansea) } \\
\text { Independent report into care of } \\
\text { older patients at Neath Port Talbot } \\
\text { and Princess of Wales Hospital, } \\
\text { Bridgend. Found serious care and } \\
\text { management failings. }\end{array}$ & $\begin{array}{l}\text { Vale of Leven } \\
\text { Hospital inquiry report into an } \\
\text { outbreak of Clostridium difficile } \\
\text { at the Vale of Leven Hospital in } \\
2007-08 \text { which resulted in at least } \\
34 \text { patient deaths. Found wide- } \\
\text { spread management and infection } \\
\text { control failings. }\end{array}$ & $\begin{array}{l}\text { Aberdeen } \\
\text { Review at Aberdeen Royal Infir- } \\
\text { mary. Found a range of concerns } \\
\text { regarding leadership, governance, } \\
\text { culture and inappropriate behav- } \\
\text { iours which have been impacting on } \\
\text { the quality of care. }\end{array}$ \\
\hline Ongoing & $\begin{array}{l}\text { Northern Trust } \\
\text { Review of care failings in the } \\
\text { Northern Trust area of Northern } \\
\text { Ireland from 2008-13 which led to } \\
\text { the deaths of II patients. }\end{array}$ & & \\
\hline
\end{tabular}


looking after the patients'. The experience of these inquiries suggested that staff had become immune to the problems experienced and for some their moral compass was off course. We need to consider why this can happen and engender a culture in which patients and staff wellbeing is our primary focus at all times.

Medical and nursing care has come a long way since reports of poor care during the Crimean War reached the UK and Florence Nightingale improved the level of basic care provided to wounded soldiers in military hospitals and founded modern nursing. Concerns about care are not new; inquiries into serious failing in care in the NHS started in the late 1960s. In 2003 the Nuffield Trust published a review of 10 inquiries between 1969 and $200 \mathrm{I}$ and concluded that while inquiries or investigations...can undoubtedly contribute to future improvement...it is far from clear that the NHS is learning all it can from failures or making the most of opportunities for improvement that they offer'; a statement which appears true today. Conversely, there is much evidence to show how other industries, including aviation and oil, have learned from past breaches in safety and adapted their practices successfully. ${ }^{4}$ Clearly, there is scope to learn from others as to how we could potentially improve our systems to prevent a recurrence of error. The application of commercial or industrial improvement measures require sensitive adaptation rather than blind adoption to ensure that in pursuing increased safety, we do not lose sight of the importance of the other dimensions of quality and compassion. We must consider if the recent 'industrialisation' of health, at least in management terms, has contributed to a loss of compassion and caring, whereby patients are treated as commodities and staff as part of a production line.

\section{A DIFFERENT APPROACH}

In seeking to reduce the likelihood of 'where next?', it is clear that we must move beyond the cycle of blame which often emerges following reports of serious failings in care and recognise the limitations of regulatory responses. This approach negatively impacts on staff morale, stifles innovation and contributes to the four common themes which have been identified and must be addressed - poor leadership, insufficient staffing, poor communication and poor professional engagement. Of those, only one (insufficient staffing) would benefit directly from a regulatory response, by building on the recommendation regarding minimum staffing made in the Francis Report, and the innovative work of the National Institute for Health and Care Excellence in developing safe nursing levels for adult in-patient wards and A\&E. ${ }^{5-7}$ We need to develop minimum staffing levels for doctors in the medical specialties and other professions in hospitals and this is urgently required for medical staff for out of hours including weekends and Hospital at Night rotas. There is strong evidence to show

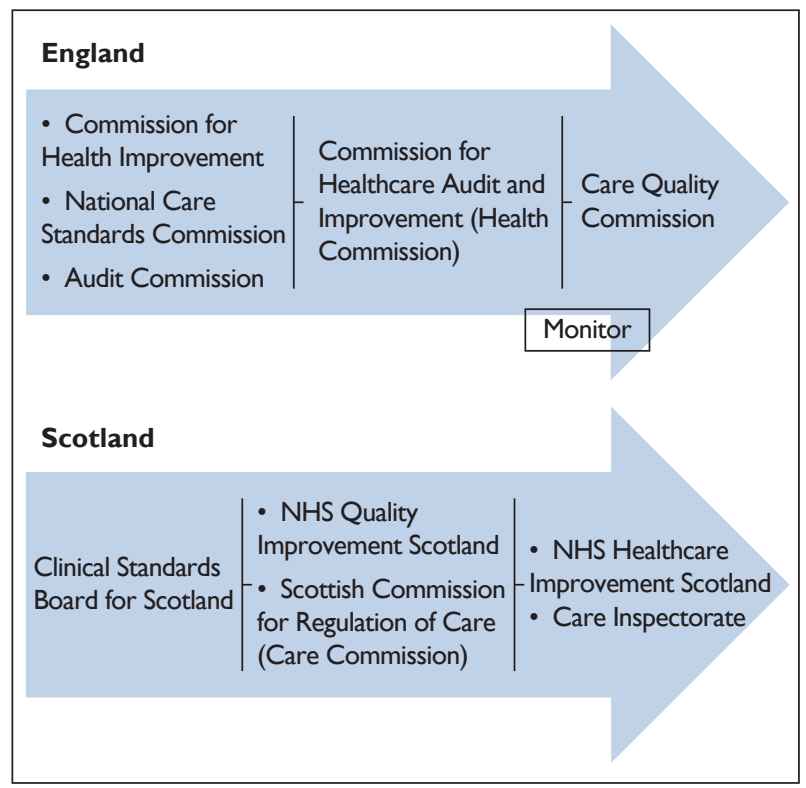

FIGURE I Restructuring of Regulatory Inspection Bodies in England and Scotland

the increased risk of death and poorer outcomes in patients when treated out of hours when staff capacity is reduced, and a solid case for developing 7-day working. ${ }^{8.9}$ Returning to the experience of the aviation industry, we would not expect passengers to accept a higher risk of their flight crashing in the evenings or at weekends due to reduced staffing or inexperience, so why should patients accept this from their NHS?

In recent years, the NHS has increased the use of locums at all grades and there is a growing problem of unfilled medical consultant positions in many specialties. ${ }^{10-12}$ It has been recognised that the role of the medical registrar, in particular, has become increasing unpopular due to the working pressures which this entails. ${ }^{13}$ The Royal College of Physicians of Edinburgh has initiated work to address this and we believe the implementation of appropriate staffing levels in a supportive environment would make medical careers more attractive and provide a more sustainable future medical workforce. ${ }^{14}$

\section{Engaging the professions}

The three remaining themes of poor leadership, poor communication and poor engagement cannot be addressed by regulation and require major cultural change within the NHS. We must ensure professionalism is a core part of healthcare roles, that all staff are valued and the workplace is enjoyable and conducive to high quality care. Indeed, a recent review by the King's Fund found that where NHS staff were more engaged and empowered, the quality of care and a range of patient outcomes (including mortality rates) were improved. ${ }^{15}$ Medical management must also be perceived as high value and we will continue to support the Faculty of Medical Leadership and Management in changing the 
perceptions and value of medical management and promoting and supporting medical leadership within the NHS.

The increasing pressures experienced by doctors, nurses and other health professionals are well-documented, including in an earlier editorial from the Royal College of Physicians of Edinburgh in response to the Francis Report. ${ }^{16}$ There is emerging evidence to suggest that the increased industrialisation of the NHS, through which NHS services are becoming increasingly viewed as commercial products and with a relentless focus on 'efficiency' rather than quality, is leading to a decrease in morale and an erosion of professionalism. ${ }^{17}$ Combine this with perpetual structural change within the NHS and the increased politicisation of health and we have the making of a perfect storm (Figure 2).

In recent years, the NHS has made much progress in developing Patient and Public Involvement. This can take many forms, from recognising patients as experts in their own health (particularly in chronic disease management) and learning from them, to involving patients in decisions about how hospital services are delivered and can be improved. Directly involving patients and public in the design of our urgent and emergency care systems would ensure their voice is heard and ensure we provided safe, pleasant and compassionate systems. Unfortunately, less progress has been made in supporting staff who work in high pressure environments.

While the NHS also makes provision for whistleblowing, this is too late in the process and damage has already occurred. Leaders must openly support a culture of open reporting of professional concerns about standards of care and more must be done to support all professions in their duty of candour. A transparent supportive environment in which the open reporting of concerns is welcomed, used as a positive learning experience and acted upon is now essential. To address these issues we believe it necessary to build on the success of Patient and Public Involvement and give similar priority to addressing and supporting the needs of NHS staff and recognising the 'people' element within the NHS, without which care could not be provided. Only by adopting a holistic approach and looking at the whole of the NHS, how it functions and its people (patients and staff), will we be able to progress.

\section{RECOMMENDATIONS AND CONCLUSION}

We believe that this approach will take time and require incremental change. To start this process, we would propose the following initial steps:

\section{Policymakers}

All political parties should commit to developing and implementing minimum staffing levels for all professions

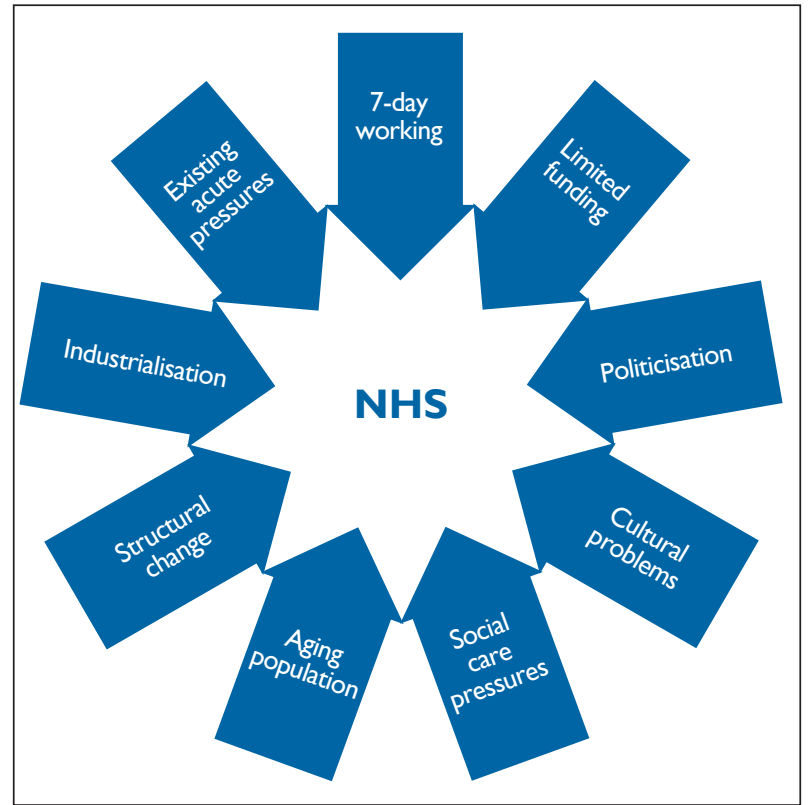

FIGURE 2 The perfect storm

within hospital settings, based upon best evidence, as a policy priority.

\section{Patients}

Building on the unprecedented level of civic engagement experienced during the recent referendum in Scotland, we would encourage patients throughout the UK to become more actively involved in their care and decisions regarding the delivery of services (by becoming more involved in managing their health, joining a local patient group, raising concerns or contacting their local MP/ MSPIAM to advocate and support improvements within the NHS).

\section{Professionals}

Doctors, nurses and other health professionals should be reminded of their value to the NHS and of their responsibility to provide the highest quality of care to patients, to continually seek to improve service delivery, to act professionally at all times and to report concerns regarding poor quality care; where they do not do so, they should be held accountable.

\section{Managers (clinical and non-clinical)}

Managers should be encouraged to support professionals in their clinical decision-making, in developing the leadership skills of those responsible for leading teams, in delivering the highest quality care and in reporting concerns; they should also work within their Boards and Trusts to foster a supportive environment in which staff are seen as valued individuals and in which innovation is encouraged.

\section{NHS Boards and Trusts}

All Boards and Trusts should be encouraged to develop, 
publish and promote policies aimed at engaging staff, understanding and responding to professional concerns and valuing staff.

\section{Royal College of Physicians of Edinburgh}

Recognising its leadership role and responsibilities in improving standards, the College should continue to advocate evidence-based health policy and to drive and encourage collaborative working for the benefit of patients, while supporting physicians throughout their careers.
While there are no guarantees, and further failings in care may emerge, the potential for 'where next?' will only reduce if we work collectively to strengthen the NHS which we all value so greatly.

\section{Acknowledgement}

The authors would like to thank Graeme McAlister, RCPE Head of Fellowship \& Membership Services, for his involvement in the preparation of this editorial.

\section{REFERENCES}

I The Mid Staffordshire NHS Foundation Trust Public Inquiry. Week 2 I (4-7 May 20I I). Transcript and witness statement from Sir lan Kennedy. http://www.midstaffspublicinquiry.com/hearings/s/306/week-twentyone-4-7-may-20I I (accessed 7 January 20I5).

2 Sir lan Kennedy: Patients at risk from Mid-Staffs care failings across NHS. Daily Telegraph, 21 January 2013.

3 Walshe K. Inquiries: Learning from failure in the NHS? London: The Nuffield Trust, 2003. http://www.nuffieldtrust.org.uk/publications/ inquiries-learning-failure-nhs (accessed 20/I/20I5).

4 Aviation Safety Reporting System. http://asrs.arc.nasa.gov (accessed 20/1/2015).

5 Final Report of the Mid Staffordshire NHS Foundation Trust Public Inquiry, February 2013 http://www.midstaffspublicinquiry.com/report (accessed 20/1/2015).

6 NICE Guidelines SGI. Safe staffing for nursing in adult inpatient wards in acute hospitals National Institute for Health and Care Excellence, July 20I4. http://www.nice.org.uk/guidance/sgl (accessed 20/I/20I5).

7 Safe staffing for nursing in A\&E Departments. NICE safe staffing guideline, draft for consultation. 16 January-12 February 2015. http://www.nice. org.uk/guidance/gid-accidentandemergencysettings/resources/ accident-and-emergency-departments-guideline-consultation3 (accessed 20/1/2015).

8 NHS Services, Seven Days a Week Forum. Evidence base and clinical standards for the care and onward transfer of acute inpatients. p9, 2.I.I. Mortality rates. http://www.england.nhs.uk/wp-content/ uploads/20 I3/I2/evidence-base.pdf (accessed 20/I/20I5).

9 Academy of Medical Royal Colleges. Seven Day Consultant Present Care, 20I2. http://www.aomrc.org.uk/doc_view/9532-seven-dayconsultant-present-care (accessed 20/I/20I5).
10 Health boards spend $€ 82 \mathrm{~m}$ on locum doctors. BBC Scotland News, 2 December 2014. http://www.bbc.co.uk/news/uk-scotland-30223609 (accessed 20/I/2015).

II Jaques $\mathrm{H}$. One in six hospitals in England paying locums more than £1000 a shift. BMJ Careers, 9 April 2013. http://careers.bmj.com/ careers/advice/view-article.html?id=200I I663 (accessed 20/I/20I5).

12 ISD Scotland/NHS. NHS Scotland Workforce. Data as at 30 June 20I4. https://isdscotland.scot.nhs.uk/Health-Topics/Workforce/ Publications/20 I4-08-26/20 I4-08-26-Workforce-Report. pdf? I5484255553 (accessed 20/I/20I5).

I3 Chaudhuri E, Mason NC, Logan S et al. The medical registrar. Empowering the unsung heroes of patient care. London: Royal College of Physicians, 2013. https://www.rcplondon.ac.uk/sites/default/files/ future-medical-registrar_I.pdf (accessed 20/I/20I5).

I4 Royal College of Physicians of Edinburgh. The Medical Registrar role restoring its status and job satisfaction. December 20l4. http://www. rcpe.ac.uk/news/medical-registrar-role-restoring-its-status-and-jobsatisfaction (accessed 20/I/20I5).

15 The King's Fund. Improving NHS care by engaging staff and devolving decision-making. July 2014. http://www.kingsfund.org.uk/publications/ articles/improving-nhs-care-engaging-staff-and-devolving-decisionmaking (accessed 20/I/20I5).

16 Dewhurst NG, Jones MC, Wilson JA. Time to refocus the NHS on quality and dignity of patient care: RCPE response to Mid Staffordshire. J $R$ Coll Physicians Edinb 20I3; 43: 3-6. http://dx.doi.org/I0.4997/ |RCPE.2013.101

17 Gerada C. Something is profoundly wrong with the NHS today. BM] Careers, 16 June 2014. http://careers.bmj.com/careers/advice/viewarticle.html?id=200 I8022\#rel (accessed 20/I/20I5). 